Article

\title{
Urban Sport-for-Development Initiatives and Young People in Socially Vulnerable Situations: Investigating the 'Deficit Model'
}

\author{
Zeno Nols *, Rein Haudenhuyse and Marc Theeboom
}

Sport \& Society Research Unit, Vrije Universiteit Brussel, 1050 Brussels, Belgium; E-Mails: zeno.nols@vub.be (Z.N.), reinhard.haudenhuyse@vub.be (R. H.), marc.theeboom@vub.be (M.T.)

* Corresponding author

Submitted: 29 January 2017 | Accepted: 25 March 2017 | Published: 29 June 2017

\begin{abstract}
Critical scholars have indicated that the assumptions underlying most sport-for-development (SFD) initiatives tend to align with a 'deficit model' of youth: young people from disadvantaged areas are uniformly deficient and in need of development, which can be achieved through sport (Coakley, 2011; Coalter, 2013). In this article, we investigated these assumptions within six urban SFD initiatives that work with young people in socially vulnerable situations in a 'first' world nation, Belgium. We conducted a survey at two moments in time amongst 14- to 25-year-old participants in order to test two assumptions: i) 'participants are deficient and in need of development'; and ii) 'participation in SFD initiatives leads to positive personal development'. We operationalised 'development' as the commonly used outcomes of perceived selfefficacy and self-esteem. These are 'household words' both inside and outside SFD research, practice, and policy and carry the assumption that boosting them will by itself foster positive outcomes. The findings refute the supposition that young people from disadvantaged urban areas are uniformly in need of more perceived self-efficacy and self-esteem and show that there is no simple and predictable change in participants' 'development'. We suggest that, in designing and researching programs, SFD stakeholders start from an open-ended bottom-up approach which is tailored to the actual life situations of young people and their individual differences and consider more interpersonal and critical conceptualisations of 'development'.
\end{abstract}

\section{Keywords}

deficit model; disadvantaged communities; self-efficacy; self-esteem; sport; sport-for-development, urban areas; youth

Issue

This article is part of the issue "Sport for Social Inclusion: Questioning Policy, Practice and Research", edited by Reinhard Haudenhuyse (Vrije Universiteit Brussel, Belgium).

(C) 2017 by the authors; licensee Cogitatio (Lisbon, Portugal). This article is licensed under a Creative Commons Attribution 4.0 International License (CC BY).

\section{Introduction}

In communities with low living standards, it is increasingly thought that sport can reach a large number of people and that it can be used as a vehicle to address a variety of social challenges such as poverty, as well as achieve non-sport development objectives (Haudenhuyse \& Theeboom, 2015; Schulenkorf, Sherry, \& Rowe, 2016). In recent years, however, the assumed potential of sport-for-development (SFD) initiatives to achieve broader social change has been the subject of considerable academic scrutiny (Schulenkorf et al., 2016; Darnell,
Chawansky, Marchesseault, Holmes, \& Hayhurst, 2016; Jones, Edwards, Bocarro, Bunds, \& Smith, 2016). One key issue within SFD highlighted by critical scholars is that many SFD policies and initiatives are imbued with paternalistic values and neoliberal philosophies that emphasise the need for individual responsibility and treat young people as problems to be solved (i.e., with flawed attitudes or displaying 'anti-social' behaviour) (Coakley, 2011; Darnell, 2012; Darnell \& Hayhurst, 2011; Rossi \& Jeanes, 2016). Scholars underlined how the assumptions underlying most SFD initiatives tend to align with a 'deficit model', which assumes that young people from 
disadvantaged areas are uniformly deficient and in need of development (Coakley, 2011; Coalter, 2013). This approach, described as 'narrow empowerment' (Lawson, 2005), highlights individual deficits while distracting attention from deficiencies within the social system that tend to make young people socially vulnerable in the first place (e.g., poverty, social inequalities) (Haudenhuyse, Theeboom, \& Nols, 2012b; Kelly, 2011; Weiss, 1997a). Furthermore, presumptions within SFD concerning individual deficits are seldom based on a systematic diagnosis of young people's social conditions and needs. According to Rossi, Lipsey and Freeman (2004), it is common for social programs to be based on faulty assumptions about both the nature and extent of the problem they address and the needs of the target population they intend to serve. This occurs because of an insufficient initial diagnosis, selective exposure or the reliance on stereotypes. These programs may have little prospect of achieving their intended effects. Thus, a systematic assessment of both young people's assumed needs and developmental change through sport can indicate which of the assumptions that lie behind the deficit model are faulty.

Therefore, the purpose of this study is to investigate the assumptions underlying a deficit model of youth within six urban SFD initiatives that work with young people living in socially vulnerable situations and disadvantaged communities in Belgium (specifically, Flandersthe northern part of Belgium-and Brussels). The aim is to highlight some of the dangers of deploying a deficit model of youth within SFD policy, practice, and research.

Regarding 'development', various scholars stated that the term is intriguingly vague, has a contentious and contested character, and is complicated, poly-vocal, and open to several interpretations (Black, 2010; Hartmann \& Kwauk, 2011; Kruse, 2006). Consequently, the term 'sport-for-development' has been defined in reference to individual, community, and societal levels, as well as in reference to several outcomes (Coakley, 2011; Schulenkorf et al., 2016). This wide array of definitions initiated calls for more conceptual and theoretical clarity within SFD (Schulenkorf \& Spaaij, 2016). In designing the research strategy for this study, our challenge was to explore which conception of 'development' was most dominant within SFD research, practice, and policy. We found that, in most SFD programs, 'development' is not defined in terms of the need for social justice, collective empowerment and action, or transformative social change at a community or institutional level (Coakley, 2011; Darnell, 2010; Hayhurst, Wilson, \& Frisby, 2010; Lawson, 2005). Instead, 'development' is mostly defined as an individual process in which socialisation experiences will produce the attributes needed to increase young people's life chances (Coakley, 2011, 2016; Darnell, 2012; Schulenkorf et al., 2016). Such an individualfocused approach is often selectively or uncritically embraced by many who fund, manage, and staff SFD initiatives, as is shown by references to so-called 'heartfelt narratives' (Hartmann \& Kwauk, 2011) and a vision of 'development' as linear and measurable in a quantitative way (Coalter, 2013; Harris \& Adams, 2015; Haudenhuyse et al., 2012b; Kay, 2012; Jeanes \& Lindsey, 2014). Therefore, in communities with low living standards and a high degree of poverty, SFD initiatives tend to focus on fostering life skills in areas such as: self-confidence, selfefficacy, and self-esteem; decision-making; leadership; public speaking; human rights, gender attitudes, and prevention of sexual violence; and knowledge about health (Coalter \& Taylor, 2010; Mwaanga \& Prince, 2016; Spaaij, Oxford, \& Jeanes, 2016). Within a deficit model, the importance of self-confidence, -efficacy, and -esteem is stressed in terms of overcoming barriers, making choices, and improving one's life chances (Coakley, 2011; Coalter \& Taylor, 2010; Mwaanga \& Prince, 2016; Spaaij et al., 2016). Despite the critique of 'neoliberal understandings', these are the most commonly used outcomes in research within sport-based youth development literature (i.e., self-confidence and self-esteem) (Jones et al., 2016; Schulenkorf et al., 2016). Also, outside of SFD, in other youth development contexts, the concept of self-esteem, for instance, has become a 'household word' on the assumption that boosting it will by itself foster positive outcomes, although evidence for such an assumption has not been found (Baumeister, Campbell, Krueger, \& Vohs, 2003; Mruk, 2013). Unfortunately, a large number of SFD practitioners and scholars within sport-based youth development contexts find it difficult to resist thinking in terms of a deficit model, thereby aligning themselves with the dominant managerialist or political rhetoric, and potentially harming young people and their self-image (Cooper, 2012; Kennelly, 2016).

Although SFD programs tend to emphasise individual deficits selectively and overstate the developmental benefits of sport, this is less often empirically and critically investigated, making analysis of this type valuable in complementing the theoretical critiques (Darnell, 2015). One of the exceptions to the scarcity of research on this theme is the work of critical scholar Fred Coalter (2013; Coalter \& Taylor, 2010), who studied the assumptions underlying the deficit model in the Global South (specifically, India and Kenya) via a quantitative pre- and postresearch design, which allowed him to measure 'needs'operationalised as a lack of perceived self-efficacy and self-esteem-and 'impact'. Coalter showed that participants were not uniformly deficient and that the programs had no simple and predictable impact. In their integrated literature review, Schulenkorf and his colleagues (2016) indicated that the majority of SFD projects are carried out in the 'Global South' and that research has largely focused on the community level, where qualitative approaches are dominant. For that reason, we placed our research focus on participants' needs and outcomes in the 'Global North' (Belgium) and opted for a quantitative research design similar to Coalter's. However, there are important distinctions between our study and Coalter's work. Firstly, Belgium is a wholly different socioeconomic and cultural context to India or Kenya. In 2014, the HDI of 
Belgium was $0,890\left(21^{\text {th }} / 188\right.$; 'very high $\left.\mathrm{HD}^{\prime}\right)$ compared to $0,609\left(130^{\text {th }} / 188\right.$; 'medium HD') and 0,548 $\left(145^{\text {th }} / 188\right.$ : 'low HD') for India and Kenya respectively (UNDP, 2017). Secondly, we took additional background variables of participants into account, some of which can be regarded as proxy-indicators of social vulnerability, and conducted more elaborate and different analyses.

We administered a survey at two moments in time amongst 14- to 25-year-old participants of SFD initiatives in order to test two assumptions within the deficit model: i) 'participants are deficient and in need of development'; and ii) 'participation in SFD initiatives leads to positive personal development'. In line with the above literature, we operationalised 'development' as the commonly used outcomes of perceived self-efficacy and selfesteem within research, practice, and policy. In line with the dominant assumptions in SFD, these simple hypotheses were formulated:

- Hypothesis 1: participants have low perceived selfefficacy;

- Hypothesis 2: participants have low self-esteem;

- Hypothesis 3: participation in the initiatives leads to an increase of perceived self-efficacy between the first (T1) and the second (T2) administration;

- Hypothesis 4: participation in the initiatives leads to an increase of self-esteem between $\mathrm{T} 1$ and $\mathrm{T} 2$.

After outlining the methods and reporting the results, we aimed to contribute to the academic debate on the deficit model and formulated practical implications for SFD stakeholders (i.e., needs assessment, understanding program mechanisms and context, conceptualisation of 'development'). Finally, we briefly suggest some concrete theoretical pathways which go beyond the deficit model and which can inform, guide, and clarify the field of SFD in the future.

\section{Methods}

\subsection{Initiatives}

The data were collected at six SFD initiatives located in three disadvantaged, super-diverse urban areas in Belgium (Brussels, Antwerp and Genk). These three cities all have areas with a high degree of poverty and hardship, school drop-out rates, unemployment, and a lack of sustainable facilities and opportunities. 'Super-diversity' is an urban reality in which citizens are characterised by a complex layering of and interaction between variables such as countries of origin, nationalities, languages, cultures, religions, statuses, and social positions (Vertovec, 2007). Thus, the term should not be misunderstood as 'ethnic-cultural diversity'. The degree of superdiversity in Belgium is highest in Brussels, Antwerp and Genk. It is within this context that the initiatives were selected using the following criteria: (1) having a track record in working with young people in socially vulner- able situations; and (2) explicitly mentioning working on young people's development. The initiatives are Antwerp Wolf Pack Basketball, Brussels Boxing Academy, Brussels Brazilian Jiu Jitsu Academy, 'Boxing Up' (Opboksen, Genk), City Pirates Football Club (Antwerp), and Kras Sport (futsal, Antwerp). These initiatives are relatively open access, but with a targeting, outreach approach designed to attract young people from the area. They can be regarded as 'sport-plus' (Coalter, 2007) clubs whose primary focus is to use sport as a tool to achieve social development outcomes. They are relatively large initiatives and some of them have hundreds of participants.

\subsection{Participants and Recruitment}

The study population comprised boys and girls that are active in the selected initiatives and are between 14 and 25 years old. Due to the vulnerable nature of the population, attention was given to obtaining a passive informed consent from young people and their parents. This recruitment approach was agreed with staff members.

\subsection{The Survey}

Prior to the survey, the initiatives outlined a theory of change in several focus groups. Their theories of change helped us to focus our research attention and resources on key aspects (and key outcomes) of the initiatives' programs (Weiss, 1997a). The formulated key outcomes were "having self-esteem" (worthy beliefs about oneself) and "believing in their own ability" (or selfconfidence/perceived self-efficacy). As discussed previously, these concepts of self-confidence/efficacy and self-esteem are also commonly used in research within sport-based youth development literature (Jones et al., 2016; Schulenkorf et al., 2016). Existing scales were used to measure perceived self-efficacy and self-esteem. Such scales are likely to be more valid and reliable than newly crafted ones and allow a comparison of the distribution of responses in specific populations (Weiss, 1997b). The survey was administered to the young people at two moments in time: at the start of the sporting season (T1; October 2015) and at the end (T2; May 2016). To take the multilingual context into account, the survey was drafted in Dutch, French, and English via the back-translation method. After piloting, the survey was completed by the participants in small groups with the first author available for clarification.

\subsubsection{Perceived Self-Efficacy}

Perceived self-efficacy can be defined as "people's judgements of their capabilities to organise and execute courses of action required to attain designated types of performances" (Bandura, 1986, p. 391). This concept influences thought patterns which relate to initiative, as well as the effort people will put into a particular activity, the extent to which they will persevere when facing ob- 
stacles, and their resilience when they face adversity ( $\mathrm{Pa}$ jares, 1996). To measure it, the General Self-Efficacy Scale (GSES) (Sherer et al., 1982), modified by Bosscher, Smit and Kempen (1997), was used. Although self-efficacy theory emphasises task-specificity, various experiences of failures and success in different domains of functioning may generate more generalised beliefs of self-efficacy that have explanatory value as well (Bosscher \& Smit, 1998). Thus, general perceived self-efficacy is akin to 'selfconfidence'. The GSES has acceptable psychometric qualities (Bosscher et al., 1997; Bosscher \& Smit, 1998). In this study, the internal consistency (Cronbach's alpha) of this scale was 0.775 , which is acceptable $(>0.70)$.

\subsubsection{Self-Esteem}

According to Mruk (2013, p. 27) "self-esteem is the lived status of one's competence at dealing with the challenges of living in a worthy way over time". The factor of competence has the conceptual room to accommodate such things as Bandura's (1986) notion of self-efficacy (Mruk, 2013). To measure self-esteem, the Rosenberg Self-Esteem Scale (RSES) was used (Franck, De Raedt, Barbez, \& Rosseel, 2008; Rosenberg, 1965; Vallieres \& Vallerand, 1990). Whereas, in recent literature, a distinction is made between a 'state' versus a 'trait' form of selfesteem, the original RSES was designed to assess a person's global trait-like self-esteem. The RSES has acceptable psychometric qualities (Franck et al., 2008; Rosenberg, 1965; Vallieres \& Vallerand, 1990). In this study, the internal consistency (Cronbach's alpha) of this scale was 0.701 , which is acceptable $(>0.70)$.

\subsubsection{Socio-Demographic and Sport Indicators}

Socio-demographic indicators were included in the survey such as: sex; age; country of birth; school trajectory (e.g., year repetition, suspension); family situation (e.g., spoken language at home, country of birth of (grand)mother); questions about perceived financial home situation; and concerns about their own future. Some of these indicators were used as proxy-indicators of social vulnerability (e.g., year repetition, school suspension, difficult financial home situation). According to Vettenburg's (1998) framework of social vulnerability, year repetition and suspension can be important indicators of a socially vulnerable trajectory and can be predictive for further school and labour market trajectories. Sport-related indicators were also included (e.g., sport frequency, length of membership).

\section{Results}

\subsection{Participant Profile}

The first administration (T1) was conducted amongst 288 young people of which $82.6 \%$ were boys ( 238 boys) and $17.4 \%$ were girls (50 girls) (Table 1 ). Because of a short- age of participants aged over 14 years old at Antwerp Wolf Pack Basketball, it was decided to lower the age group at this initiative to 12 years old $(n=14)$. Also at City Pirates Football Club, one team (U14) had several 13-year-old players $(n=20)$ who were also questioned. For these younger people (12-13 year olds), the researcher ensured that extra attention was given in advance to clarify the questions. Investigating participants' characteristics showed that the participants were, in general, a very ethnic-culturally diverse, multilingual group of young people.

The proxy-indicators of social vulnerability were analysed to investigate to what degree the initiatives reached young people living in socially vulnerable situations. Firstly, more than half $(54.0 \% ; n=150)$ of the participants had repeated a school year at least once. This is a relatively high number since research shows that, at the age of 15, in Flanders, 'only' $27 \%$ of the students repeated their year at least once compared to $47 \%$ in the Wallonia-Brussels Federation, while the OECD mean was 13\% (Oproep Voor een Democratische School, 2014). Secondly, there was the high percentage of school suspension (19.2\%), with $10.9 \%$ of the young people suspended twice or more. Furthermore, the sport coaches confirmed that many of their participants did indeed find themselves in socially vulnerable situations.

For the second administration (T2), due to temporary injuries, players' movements (to other initiatives or within the initiative), and other (unknown) reasons, there was a drop-out rate of $44,4 \%(n=128)$. Therefore, the second administration (T2) was conducted amongst 160 young people of which $85,6 \%$ were boys ( 137 boys) and $14,4 \%$ were girls ( 23 girls). A comparison between those participants that dropped out and those that completed the survey twice showed that drop-outs have a significantly higher age $(p=0.018)$ and have been suspended significantly more often $(p<0.001)$. Drop-outs did not differ significantly with regard to perceived selfefficacy ( $p=0.615)$, self-esteem $(p=0.672)$, financial home situation $(p=0.075)$, sex $(p=0.135)$, year repetition ( $p=0.061)$, or length of membership $(p=0.066)$.

\subsection{Investigating the Deficit Model}

Investigating the deficit model, implicitly or explicitly present in much SFD rhetoric, we found that the young people in the initiatives were not uniformly deficient and in need of development (i.e., low perceived selfefficacy and self-esteem). In general, the average score on perceived self-efficacy ( $n=288$ ) was 25.18 on a maximum of 36, with a standard deviation of 5.247 (Table 2). The range of the perceived self-efficacy scores was 33, with a minimum score of 3 and a maximum of 36 . Perceived self-efficacy scores between 20 and 30 are considered normal. The data showed that 33 young people had a score under 20 (representing low scores), while 44 young people had a score above 30 (representing high scores). The skewness of the perceived self-efficacy 
Table 1. Participants' characteristics and proxy-indicators of social vulnerability.

\begin{tabular}{|c|c|}
\hline & All SFD initiatives \\
\hline Respondents & $100 \%(n=288)$ \\
\hline Boys & $82.6 \%(n=238)$ \\
\hline Girls & $17.4 \%(n=50)$ \\
\hline Mean age & 16.50 (SD 3.30) \\
\hline First year at the club & $44.5 \%(n=126)$ \\
\hline Two years at the club & $16.3 \%(n=46)$ \\
\hline Three years at the club & $9.5 \%(n=27)$ \\
\hline Four years at the club & $4.9 \%(n=14)$ \\
\hline More than four years at the club & $24.7 \%(n=70)$ \\
\hline Practice sport once a week (at the club) & $15,8 \%(n=44)$ \\
\hline Practice sport twice a week & $21.1 \%(n=59)$ \\
\hline Practice sport three times a week & $26.2 \%(n=73)$ \\
\hline Practice sport four times a week & $23.7 \%(n=66)$ \\
\hline Practice sport more than four times a week & $13.3 \%(n=37)$ \\
\hline Belgian nationality & $69.8 \%(n=201)$ \\
\hline Non-Belgian nationality & $30.2 \%(n=87)$ \\
\hline Roots in migration ( 3 generations) & $85.8 \%(n=247)$ \\
\hline No roots in migration & $14.2 \%(n=41)$ \\
\hline Newcomers ( $<5$ years) in Belgium & $10.1 \%(n=29)$ \\
\hline More than 5 years in Belgium & $18.1 \%(n=52)$ \\
\hline Living in Belgium all my life & $71.9 \%(n=207)$ \\
\hline At least speaking Dutch and/or French at home & $86.1 \%(n=248)$ \\
\hline Speaking (an)other language(s) at home & $13.9 \%(n=40)$ \\
\hline Still at school & $81.1 \%(n=227)$ \\
\hline In further education & $10.4 \%(n=29)$ \\
\hline Working & $7.2 \%(n=20)$ \\
\hline Looking for work & $1.4 \%(n=4)$ \\
\hline Primary school & $3.5 \%(n=8)$ \\
\hline General school & $44.5 \%(n=101)$ \\
\hline Technical school & $24.7 \%(n=56)$ \\
\hline Vocational school & $25.6 \%(n=58)$ \\
\hline Special needs school & $1.8 \%(n=4)$ \\
\hline Repeated year & $54.0 \%(n=150)$ \\
\hline Ever been suspended & $19.2 \%(n=53)$ \\
\hline Easy financial home situation & $52.5 \%(n=143)$ \\
\hline Rather easy financial home situation & $31.1 \%(n=85)$ \\
\hline Rather difficult financial home situation & $12.5 \%(n=34)$ \\
\hline Difficult financial home situation & $4.0 \%(n=11)$ \\
\hline
\end{tabular}

Table 2. Mean scores T1.

\begin{tabular}{llllll}
\hline & Mean & Std. Dev & Min-max (range) & Skewness & Kurtosis \\
\hline Perceived self-efficacy (0-36) & 25.18 & 5.25 & $3-36(33)$ & -0.603 & 1.049 \\
Self-esteem (0-30) & 21.69 & 3.99 & $8-30(22)$ & -0.333 & 0.491 \\
\hline
\end{tabular}

scores was -0.603 (small left skew) and the kurtosis (peakedness) was 1.049 (mesokurtic, but slightly thinner). Using additional testing with P-P Plots, Q-Q Plots, and One-Sample Kolmogorov-Smirnov Test $(p>0.05)$, it could be said that the scores for perceived self-efficacy are normally distributed (Figure 1). These results refute hypothesis 1 which states that participants have low perceived self-efficacy.

In general, the average score for self-esteem ( $n=288$ ) was 21.69 on a maximum of 30 , with a stan- 


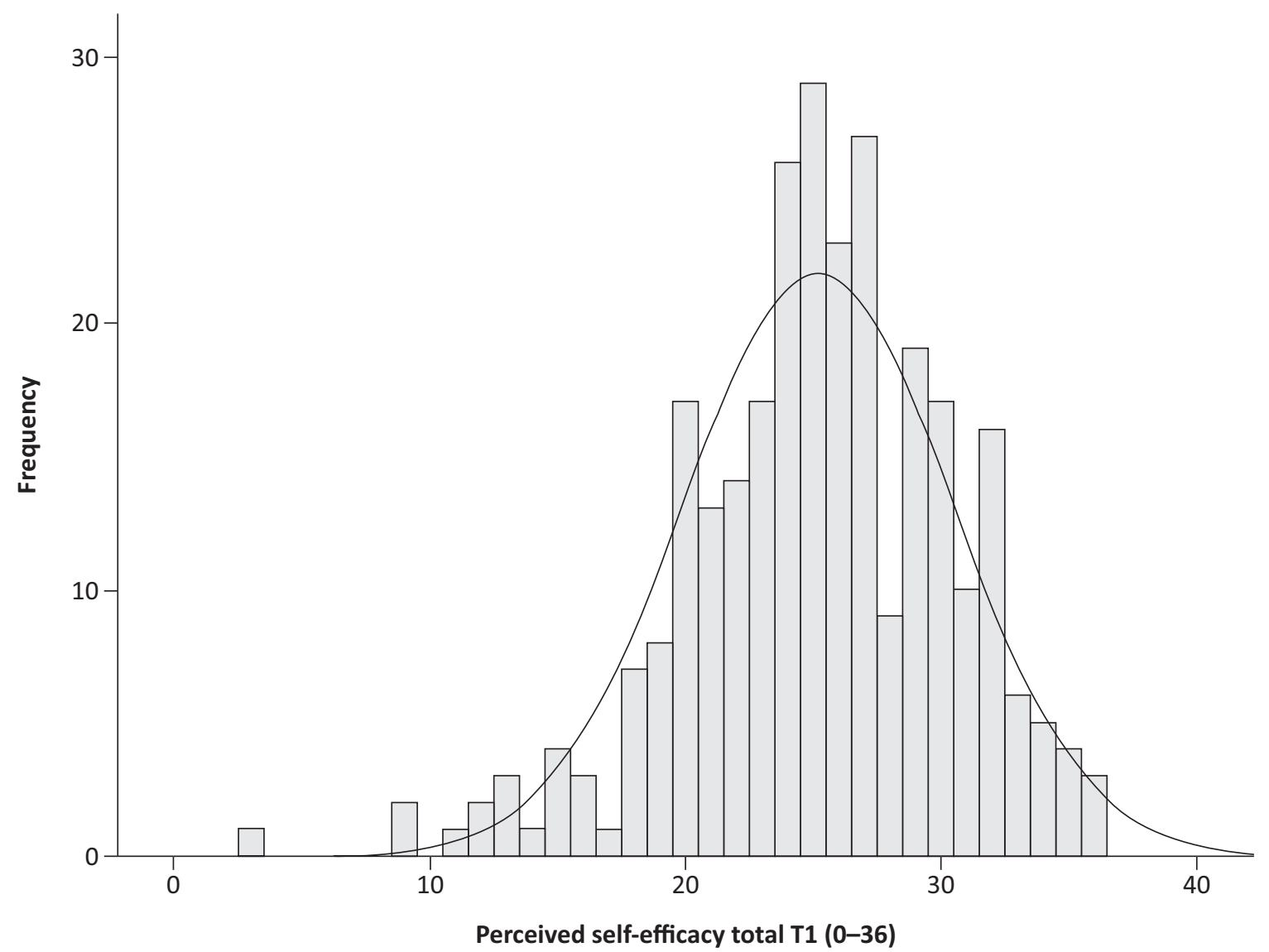

Figure 1. Perceived self-efficacy total at T1.

dard deviation of 3.986 (Table 2). The range of the selfesteem scores was 22, with a minimum score of 8 and a maximum of 30 . Self-esteem scores between 15 and 25 are considered "normal". The data showed that 11 young people had a score under 15 (representing low scores), while 53 young people had a score above 25 (representing high scores). The skewness of the selfesteem scores was -0.333 (very small left skew) and the kurtosis was 0.491 (normal mesokurtic). Using additional testing with P-P Plots, Q-Q Plots, and One-Sample Kolmogorov-Smirnov Test ( $p>0.05)$, it could be said that the scores for self-esteem were normally distributed (Figure 2). These results refute hypothesis 2 which states that participants have low self-esteem.

\subsection{Testing Differences}

The parametric one way ANOVA test $(n=288)$ indicated a significant difference $(p<0.001$ ) in perceived selfefficacy scores with boys (25.70) scoring higher than girls (22.70). A similar difference was found in self-esteem scores, with boys $(22.08)$ scoring higher $(p<0.001)$ than girls (19.84). Furthermore, there was a significant difference ( $n=288 ; p=0.009$ ) in the perceived self-efficacy scores between those who speak a language at home which is not Dutch or French (23.18) and those who speak at least Dutch or French at home (25.50). Such a difference was not found for self-esteem $(p=0.978)$.
There was also a significant difference ( $n=4282$; $p<0.001$ ) in self-esteem with regard to concerns about their own future: young people who sometimes to very often have concerns about their own future scored lower (21.13) than those who have no concerns (22.99). Such a difference was not found for perceived self-efficacy $(p=0.070)$.

In the entire group, there were no significant differences found for perceived self-efficacy and self-esteem with regard to age ( $p=0.928$ and $p=0.949$ respectively), year repetition (i.e., repeated a year at school or not) ( $p=0.053$ and $p=0.122$ ), suspension (i.e., suspended or not) ( $p=0.969$ and $p=0.806)$, length of membership (i.e., been a member one year to more than 4 years) ( $p=0.416$ and $p=0.162$ ), sport frequency (i.e., practice sport once to more than 4 times a week) ( 0.419 and 0.801 ), financial home situation (i.e., easy to difficult) ( $p=0.077$ and $p=0.838$ ), and time living in Belgium (i.e., been in Belgium for more than 5 years or not) $(p=0.155$ and 0.404).

\subsection{Investigating Developmental Changes}

Paired-samples t-tests (Table 3) showed no significant difference in perceived self-efficacy $(p=0.791)$ and selfesteem ( $p=0.885)$ between T1 and T2. However, when we split the group into participants who increased their scores on the one hand and those who showed a de- 


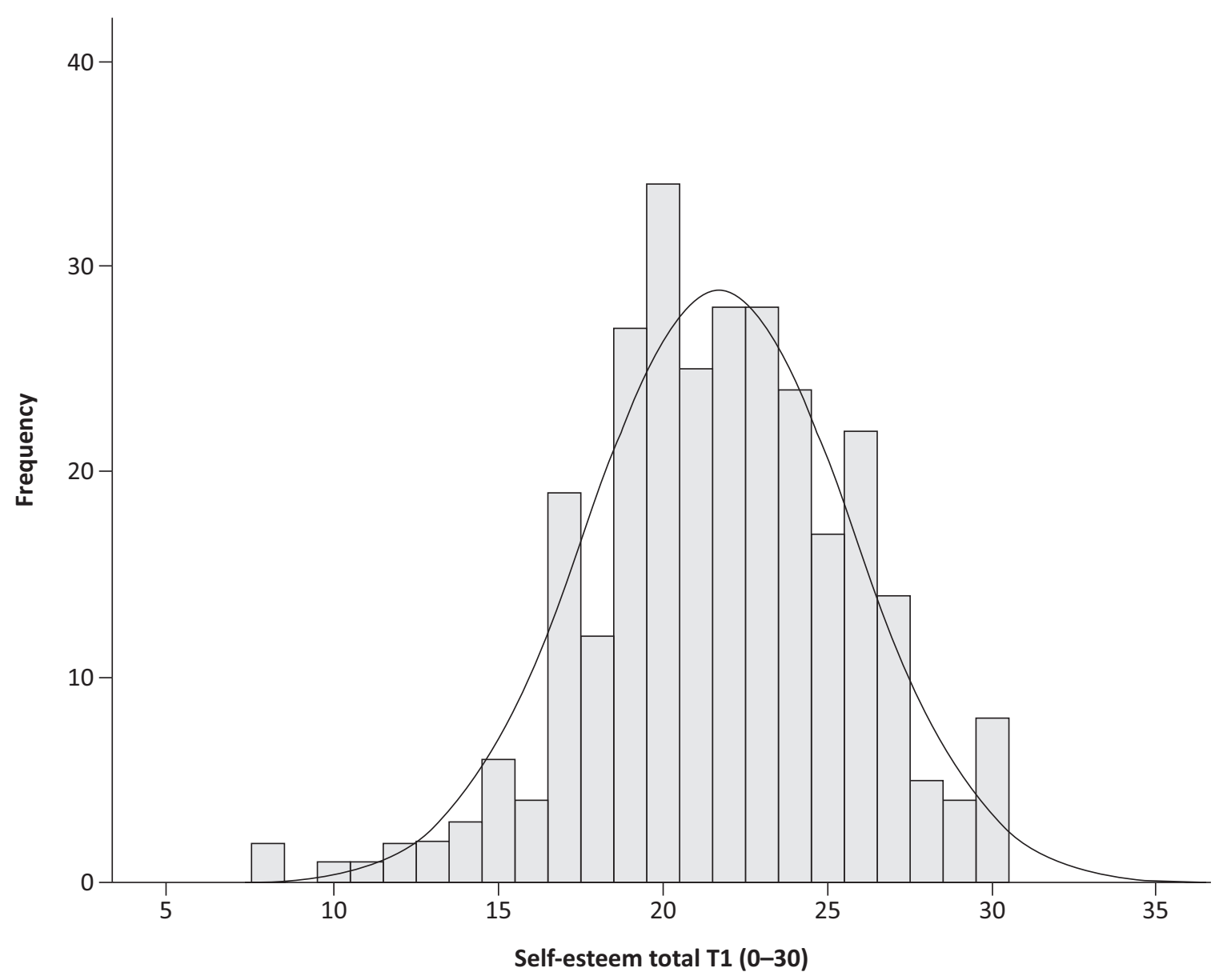

Figure 2. Self-esteem total at T1.

Table 3. Developmental changes.

\begin{tabular}{|c|c|c|c|c|c|}
\hline & Mean T1 & Mean T2 & Difference (T2-T1) & $\mathbf{t}$ & $\mathbf{p}$ \\
\hline Perceived self-efficacy (total) $(n=160)$ & 25.22 & 25.12 & -0.100 & 0.265 & 0.791 \\
\hline Self-esteem (total) $(n=160)$ & 21.83 & 21.78 & -0.044 & 0.144 & 0.885 \\
\hline Perceived self-efficacy (increases) $(n=61)$ & 22.67 & 27.10 & 4.426 & -8.853 & 0.000 \\
\hline Perceived self-efficacy (decreases) $(n=77)$ & 27.12 & 23.40 & -3.714 & 13.550 & 0.000 \\
\hline Self-esteem (increases) $(n=64)$ & 20.33 & 23.91 & 3.578 & -12.591 & 0.000 \\
\hline Self-esteem (decreases) $(n=73)$ & 23.40 & 20.16 & -3.233 & 11.289 & 0.000 \\
\hline
\end{tabular}

crease in scores on the other, significant changes were found for both perceived self-efficacy and self-esteem ( $p$ values all below 0.001). These increases and decreases thus cancel each other out in total, but do represent two separate meaningful trends (see next section 'beyond averages').

\subsubsection{Beyond Averages}

Just as the young people cannot be regarded as uniformly deficient or of low perceived self-efficacy and selfesteem, the changes between T1 and T2 were varied and certainly not uni-directional. There were high levels of adjustment of scores between the two administrations of the survey $(86.2 \%$ for perceived self-efficacy and $85.6 \%$ for the self-esteem scores). For perceived self-efficacy,
$38.1 \%(n=61)$ of the participants had an increase in their score while $48.1 \%(n=77)$ had a decrease in their score. There were also participants who had no changes in their perceived self-efficacy $(13.8 \% ; n=22)$. For self-esteem, $40 \%(n=64)$ of the participants had an increase in their score while $45.6 \%(n=73)$ had a decrease in their score. There were also participants that had no changes in their self-esteem (14.4\%; $n=23)$.

A scattergram represents these individual changes visually (see Figure 3). A horizontal line was placed where the difference between T1 and T2 was 0 . A vertical line was placed on the mean score of T1. Each dot represents an individual respondent's score and the degree to which their score (i.e., perceived self-efficacy, selfesteem) changed between the two survey administrations (i.e., T1 and T2). The top left and bottom right 
quadrants could be seen as the most interesting when investigating developmental changes. A scatter dot is plotted with the $y$-axis representing the difference between the first and second administration (i.e., increase or decrease) and the $x$-axis representing the individual result on the first survey score (i.e., T1).

\begin{tabular}{|c|c|}
\hline $\begin{array}{c}\text { Before score } \\
\text { below average } \\
\text { and then } \\
\text { increased }\end{array}$ & $\begin{array}{c}\text { Before score } \\
\text { above average } \\
\text { and then } \\
\text { increased }\end{array}$ \\
\hline $\begin{array}{c}\text { Before score } \\
\text { below average } \\
\text { and then } \\
\text { decreased }\end{array}$ & $\begin{array}{c}\text { Before score } \\
\text { aboverage } \\
\text { and then } \\
\text { decreased }\end{array}$ \\
\hline
\end{tabular}

Figure 3. Guide to reading the scattergrams.

For perceived self-efficacy, $23,13 \%$ had a score below the average on the first administration and their score on the second administrations indicated an increased perceived self-efficacy (top left quadrant). 31,25\% of the young people had a score above the average on the first adminis- tration and the scores on the second administration indicated a decreased perceived self-efficacy (bottom right quadrant) (Figure 4).

For self-esteem, $25 \%$ had a score below the average on the first administration and their score of the second administrations indicated an increased self-esteem (top left quadrant). $26,25 \%$ of the young people had a score above the average on the first administration and their scores on the second administration indicated a decreased self-esteem (bottom right quadrant) (Figure 5).

In other words, the diverse groups of participants were affected in a variety of ways and this varied between the initiatives. The hypotheses that all participants indicate an increase of their perceived self-efficacy (hypothesis 3 ) and self-esteem (hypothesis 4) between the first (T1) and the second (T2) administrations can be rejected.

\section{Discussion}

The purpose of our study was to systematically analyse two assumptions within the individual-centred deficit model of youth: i) 'participants are deficient and in need of development'; and ii) 'participation in SFD initiatives leads to positive personal development'. Before discussing the key issues, we want to stress that measuring developmental change in social sciences is conceptu-

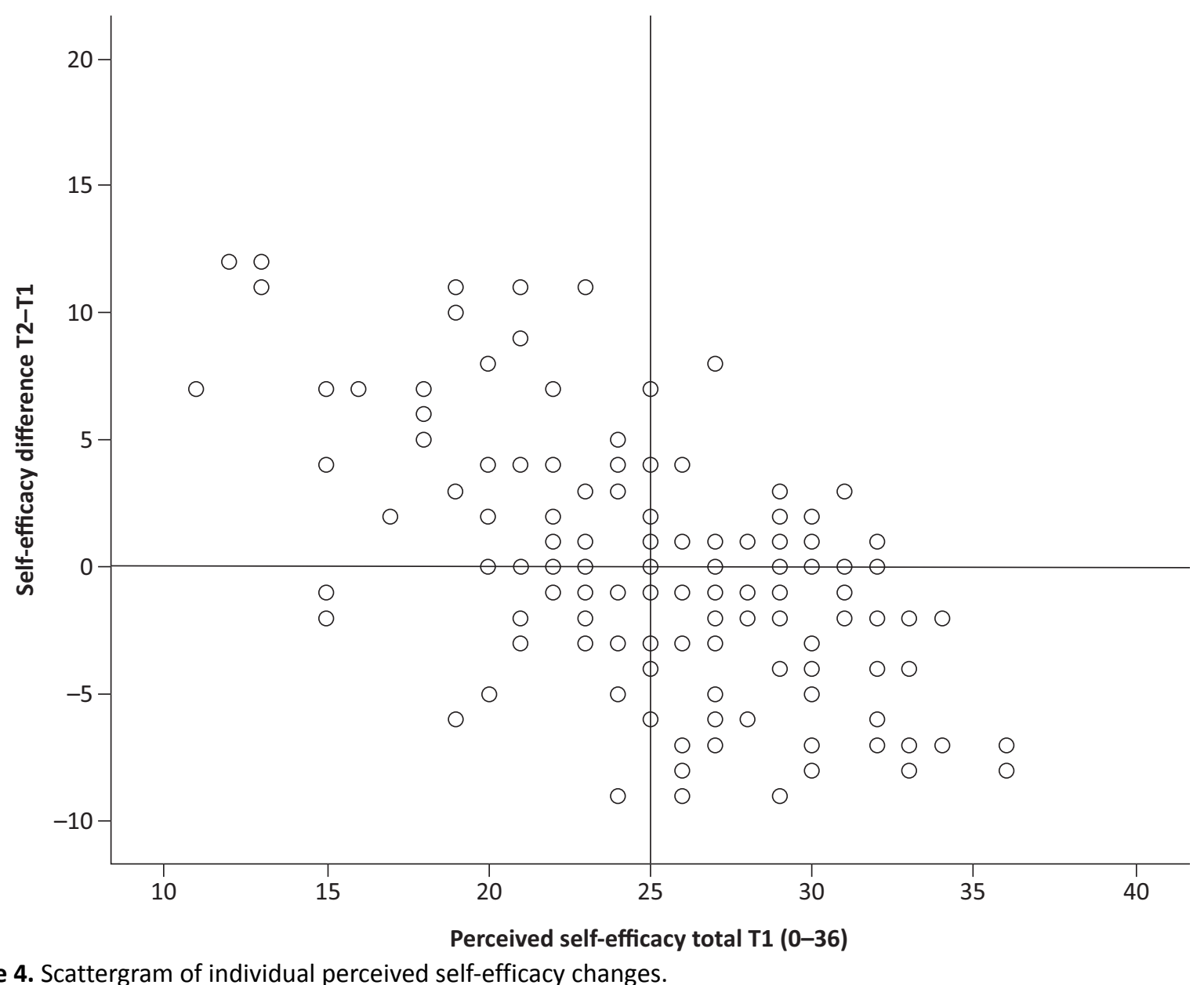

Figure 4. Scattergram of individual perceived self-efficacy changes. 


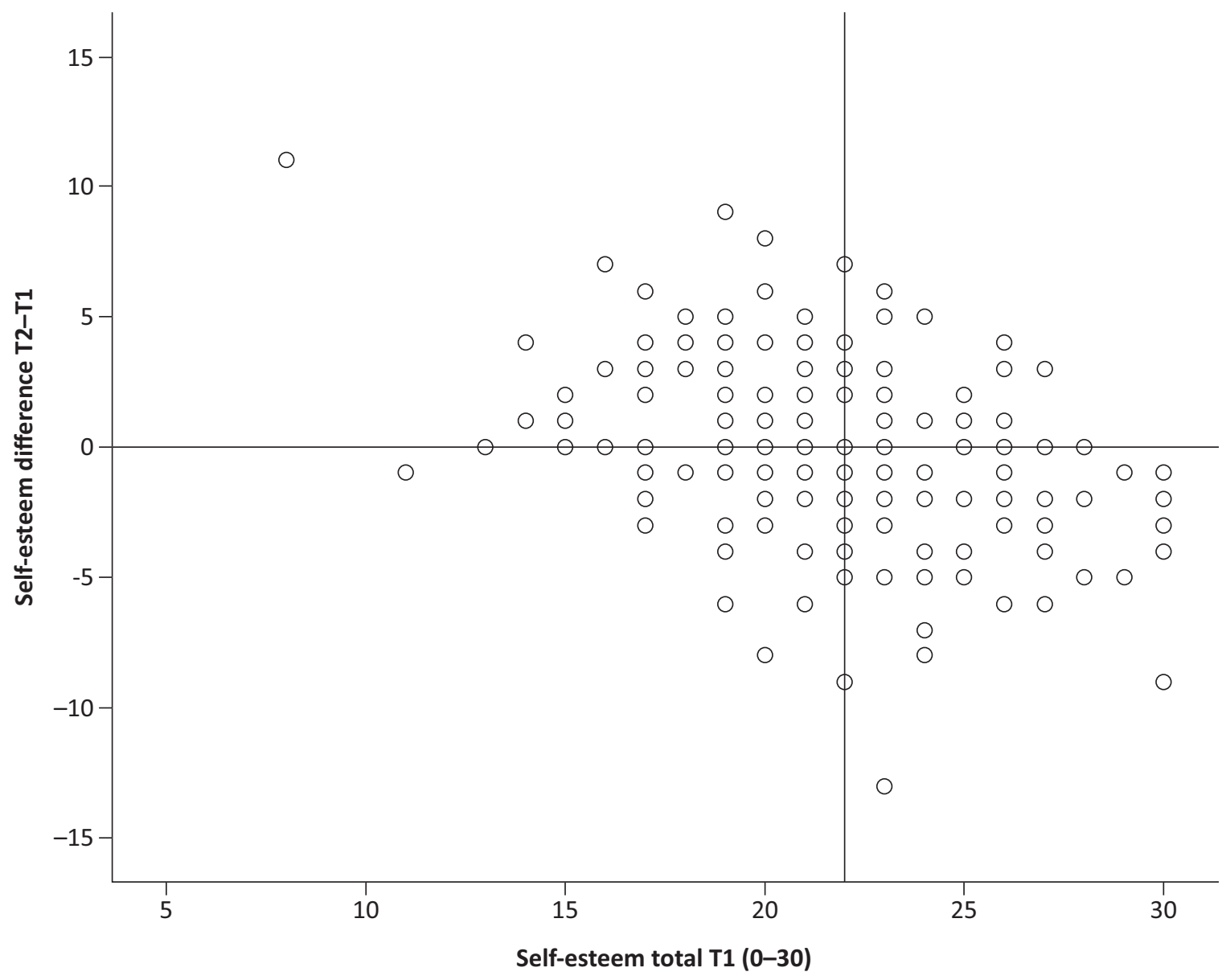

Figure 5. Scattergrams of individual self-esteem changes.

ally and methodologically challenging, which makes the interpretation of data tricky. Several limitations to this study's research design should be taken into account. Firstly, participation in the initiatives was voluntary and participants who took part are likely to have a reasonable degree of perceived self-efficacy and self-esteem. As a result, young people that are in the most vulnerable situations might not participate in these initiatives, even if they set up a targeting, outreach approach. Still, our data sources indicated that the investigated SFD initiatives attract a large number of young people who find themselves in socially vulnerable situations. Secondly, any changes that might be revealed in the data are not necessarily the result of participation in the initiatives. In social sciences, it is difficult to isolate the 'sport' or 'program' effect from other contextual influences (e.g., family, peers, school, public space) and from more general developmental changes young people might undergo. Thirdly, when developmental changes do appear, it usually happens slowly and in very slight ways. Since we do not know if and how soon the expected developmental change is likely to appear, a time span of 6 to 8 months might be relatively short (Spaaij et al., 2016).

Despite these limitations, the data raise questions about the assumptions underpinning most SFD rhetoric. The first key issue is that young people from disad- vantaged neighbourhoods cannot be regarded as uniformly deficient in relation to the assumed deficits of perceived self-efficacy and self-esteem. Not all participants had low perceived self-efficacy and low self-esteem. On the contrary, there was a normal distribution of selfevaluations, comparable to other populations (Bosscher et al., 1997; Schmitt \& Allik, 2005). Groups of young people living in disadvantaged neighbourhoods include some with relatively high self-evaluations, some with low self-evaluations, and most with scores somewhere in the middle. The results refute the assumption that most young people living in disadvantaged communities need more perceived self-efficacy and self-esteem and, as such, warn against over-generalising about personal developmental needs. These results confirm the previous findings of research conducted in the Global South (Coalter, 2013; Coalter \& Taylor, 2010). Our analysis in disadvantaged urban areas of the Global North (Belgium) also showed that there were no significant differences for perceived self-efficacy and self-esteem regarding age, year repetition, suspension, length of membership, sport frequency, financial home situation, or length of time living in Belgium. There were, however, significant differences between boys (higher) and girls for both concepts. Further, those who speak a language at home which is not Dutch or French scored significantly lower 
on perceived self-efficacy than those who speak at least Dutch or French at home. Also, young people who sometimes to very often have concerns about their own future scored significantly lower on self-esteem than those who have no such concerns. As Rossi and his colleagues (2004) stated, there are hardly any social problems that can be easily and convincingly described in terms of simple and unambiguous characteristics of the individuals experiencing those problems. Therefore, the first implication for SFD stakeholders designing and researching SFD programs is to pay more attention to the needs assessment of young people by starting with an open-ended bottomup approach that is tailored to the actual life situations of young people and their individual differences, instead of relying on pre-defined, abstract ideas (Cooper, 2012; Giulianotti, Hognestad, \& Spaaij, 2016; Haudenhuyse et al., 2012b; Haudenhuyse, Theeboom, \& Coalter, 2012a).

The second key issue is that the outcomes measured amongst participants were varied and certainly not unidirectional (i.e., there were increases, decreases, or even no change). There was no simple and predictable change in young people's 'development', as might be expected on the basis of previous research (Coalter, 2013; Coalter \& Taylor, 2010). Evidently, starting from the inaccurate assumption that young people are uniformly deficient, it may be expected that hardly any positive change (i.e., increase) would occur for participants with already high self-evaluations. The overall picture is that many participants with lower than average self-evaluations improved their score and many with initially higher than average self-evaluations showed a decrease. This tendency might be influenced by the statistical phenomenon of 'regression to the mean'. Such decreases should not necessarily be seen as a negative outcome. It may reflect a more considered approach to the completion of the survey on the second administration, or an adjustment to healthier levels (e.g., less narcissistic or anti-social self-esteem (Mruk, 2013)) due to a practical experience or social relationships inside or outside the initiative. Likewise, for participants that had no changes in their self-evaluation, such status-quo should not necessarily be seen as a negative outcome or as evidence that SFD does not work. It might be that a participant developed lower levels of perceived self-efficacy and/or self-esteem outside the SFD initiative but developed higher levels inside the initiative. It might have been the other way around, although the latter participant is likely to quit the initiative for that reason (i.e., drop out). To think that all young people are deficient and participation in SFD initiatives automatically change self-beliefs in a 'positive' sense would ignore the complexity of social change. Therefore, the second implication for SFD stakeholders is to try to understand 'how or why a programme works, for whom, in what circumstances' and concentrate their 'fire' on vital program mechanisms and the contexts in which they operate for various groups of participants (Pawson, 2006). In line with this, Kay (2012) stated that it is questionable whether 'robust' levels of knowledge are achiev- able, and suggested that other types of knowledge (i.e., qualitative, 'understanding') may be more appropriate, valid and obtainable. According to Jeanes and Lindsey (2014), more nuanced and subtle 'understandings' are likely to enhance practice and contribute to the recognition of SFD as a more mature field that can contribute to a broader development effort.

The third key issue is that even if some young people could benefit from higher perceived self-efficacy or selfesteem levels-or any other individual-focused concept (e.g., resilience, a part of self-efficacy, or leadership)and even if participation in SFD initiatives did lead to an improvement in those levels, it remains essential to question what these outcomes are, whose interests they serve, and how they are related to young people's life chances or social vulnerability (Coalter, 2013; Darnell \& Hayhurst, 2011; Jeanes \& Lindsey, 2014; Spaaij et al., 2016). Critical scholars have argued that decontextualised and atheoretical analyses of the role of sport in development are not only simplistic and inaccurate in ascribing socially transformative abilities to sport, but also obscure the contingent nature of achieving outcomes and the broader context of development politics on the community, urban, national and/or international levels (e.g., power, ideology, welfare system) (Coalter, 2013; Darnell \& Hayhurst, 2011). A narrow approach to development which overemphasises individual agency and distracts from such broader contextual issues will reproduce vulnerability despite any 'targeted intervention' (Haudenhuyse et al., 2012b; Kelly, 2011; Lawson, 2005; Weiss, 1997a). Nevertheless, SFD initiatives aimed at young people in socially vulnerable situations can be valuable in the sense that participation may possibly help some of the young people to have more self-confidence and self-esteem and, in turn, stand 'stronger' in mainstream society and its mainstream institutions. It might be asked if this should be the core social mission of SFD initiatives. Therefore, the third implication for SFD stakeholders may be to employ fewer intrapersonal and more interpersonal and critical conceptualisations of 'development' (e.g., supportive networks), which might be more valuable and beneficial when working with young people in socially vulnerable situations, as they take actual needs as a starting point.

\section{Conclusion}

We suggest that, if SFD stakeholders want to help young people in socially vulnerable situations, when designing and researching programs, priority should be given to disengaging from the dominant individual-centred deficit model of youth. There should be engagement in an open-ended bottom-up approach that critically assesses young people's needs by addressing their actual life situations and individual differences, and that considers more interpersonal and critical conceptualisations of 'development' (Haudenhuyse et al., 2012b). However, taking into account the broader context of social exclusion 
and development politics (Coalter, 2013; Darnell \& Hayhurst, 2011), together with the impact of the current austerity climate in several 'first' world nations (Parnell, Spracklen, \& Millward, 2016), the future participation in mainstream society of young people in socially vulnerable situations is likely to be less than successful if broader societal change (e.g., in education or poverty reduction policies) does not occur at the same time (Hayhurst, Giles, \& Wright, 2016). Critical theories at the crossroads of sociology, pedagogy, and development studies (e.g., Freire's critical pedagogy or Sen's capability approach) might serve as valuable alternative pathways which lead beyond the dominant, symbolically violent assumptions that are present within contemporary society and therefore also in SFD. Such critical theories can inform and guide research designs, data collection, analyses, and interpretations and, in turn, contribute to the conceptual and theoretical clarity that the field of SFD has been welcoming for quite some time.

\section{Acknowledgements}

The authors are grateful for the collaboration from Antwerp Wolf Pack Basketball, Brussels Boxing Academy, Brussels Brazilian Jiu Jitsu Academy, 'Boxing Up' (Opboksen), City Pirates Football Club, and Kras Sport in sharing their viewpoints and advice for this study. They would also like to acknowledge the invaluable advice received from Dr. Fred Coalter, Dr. Ramon Spaaij, Dr. Veerle Vyncke, Dr. An Nuytiens and Drs. Pieter Debognies. They wish to thank the editors and anonymous reviewers at Cogitatio Press for their comments on earlier versions of this article. The first author would like to thank Tine D'aes. Above all, the authors are grateful to the young people who participate in this ongoing study and share their experiences, thoughts, and time.

\section{Conflict of Interests}

The authors declare no conflict of interests.

\section{References}

Bandura, A. (1986). Social foundations of thought and action: A social cognitive theory. Englewood Cliffs, NJ: Prentice-Hall.

Baumeister, R. F., Campbell, J. D., Krueger, J. I., \& Vohs, K. D. (2003). Does high self-esteem cause better performance, interpersonal success, happiness, or healthier lifestyles? Psychological Science in the Public Interest, 4(1), 1-44.

Black, D. (2010). The ambiguities of development: Implications for 'development through sport'. Sport in Society, 13(1), 121-129. doi:10.1080/ 17430430903377938

Bosscher, R., \& Smit, J. (1998). Confirmatory factor analysis of the General Self-Efficacy Scale. Behaviour Research and Therapy, 36(3), 339-343.
Bosscher, R., Smit, J., \& Kempen, G. (1997). Algemene competentieverwachtingen bij ouderen. Een onderzoek naar de psychometrische kenmerken van de Algemene Competentieschaal (ALCOS). Nederlands Tijdschrift voor de Psychologie, 52, 239-248.

Coakley, J. (2011). Youth sports: What counts as "positive development?". Journal of Sport \& Social Issues, 35(3), 306-324.

Coakley, J. (2016). Positive Youth Development through sport. Myths, beliefs and realities. In N. L. Holt (Ed.), Positive Youth Development in sport. London, UK: Routledge.

Coalter, F. (2007). A wider social role for sport: Who's keeping the score? London, UK: Routledge.

Coalter, F. (2013). Sport for Development. What game are we playing? London, UK: Routledge.

Coalter, F., \& Taylor, J. (2010). Sport-for-development impact study: A research initiative funded by Comic Relief and UK Sport and managed by International Development through Sport. Stirling, UK: University of Stirling.

Cooper, C. (2012). Imagining 'radical' youth work possibilities-Challenging the 'symbolic violence' within the mainstream tradition in contemporary state-led youth work practice in England. Journal of Youth Studies, 15(1), 53-71. doi:10.1080/ 13676261.2011.618489

Darnell, S. C. (2010). Sport, race, and bio-politics: Encounters with difference in "Sport for Development and Peace" internships. Journal of Sport and Social Issues, 34, 396-417.

Darnell, S. C. (2012). Sport for development and peace: A critical sociology. London, UK: A\&C Black.

Darnell, S. C. (2015). Sport for development: What game are we playing? International Journal of Sport Policy and Politics, 7(2), 315-317. doi:10.1080/ 19406940.2013.856335

Darnell, S. C., \& Hayhurst, L. M. (2011). Sport for decolonization exploring a new praxis of sport for development. Progress in Development Studies, 11(3), 183-196.

Darnell, S. C., Chawansky, M., Marchesseault, D., Holmes, M., \& Hayhurst, L. (2016). The state of play: Critical sociological insights into recent 'Sport for Development and Peace' research. International Review for the Sociology of Sport, 1-19. doi:10.1177/1012690216646762

Franck, E., De Raedt, R., Barbez, C., \& Rosseel, Y. (2008). Psychometric properties of the Dutch Rosenberg SelfEsteem Scale. Psychologica Belgica, 48(1), 25-35.

Giulianotti, R., Hognestad, H., \& Spaaij, R. (2016). Sport for development and peace: Power, politics, and patronage. Journal of Global Sport Management, 1(13), 129-141. doi:10.1080/24704067.2016.1231926

Harris, K., \& Adams, A. (2015). Power and discourse in the politics of evidence in sport for development. Sport Management Review. doi:10.1016/ j.smr.2015.05.001 
Hartmann, D., \& Kwauk, C. (2011). Sport and development: An Overview, critique, and reconstruction. Journal of Sport and Social Issues, 35, 284-305. doi:10.1177/0193723511416986

Haudenhuyse, R., \& Theeboom, M. (2015). Introduction to the special issue "Sport for Social Inclusion: Critical Analyses and Future Challenges". Social Inclusion, 3(3), 1-4. doi:10.17645/si.v3i3.381

Haudenhuyse, R., Theeboom, M., \& Coalter, F. (2012a). The potential of sports-based social interventions for vulnerable youth: Implications for sport coaches and youth workers. Journal of Youth Studies. doi:10.1080/13676261.2012.663895

Haudenhuyse, R., Theeboom, M., \& Nols, Z. (2012b). Sports-based interventions for socially vulnerable youth: Towards well-defined interventions with easyto-follow outcomes? International Review for the Sociology of Sport. doi:10.1177/1012690212448002

Hayhurst, L. M. C., Giles, A., \& Wright, I. (2016). Biopedagogies and Indigenous knowledge: Examining sport for development and peace for urban Indigenous young women in Canada and Australia. Sport, Education and Society, 21(4), 549-569. doi:10.1080/ 13573322.2015.1110132

Hayhurst, L., Wilson, B., \& Frisby, W. (2010). Navigating neoliberal networks: Transnational Internet platforms in Sport for Development and Peace. International Review for the Sociology of Sport, 46(3), 315-329.

Jeanes, R., \& Lindsey, I. (2014). Where's the "evidence?" Reflecting on monitoring and evaluation within Sportfor-Development. In K. Young \& C. Okada (Eds.), Sport, social development and peace (research in the sociology of sport, volume 8) (pp. 197-217). Bingley, UK: Emerald Group Publishing Limited.

Jones, G., Edwards, M., Bocarro, N., Bunds, K., \& Smith, J. (2016). An integrative review of sportbased youth development literature. Sport in Society. doi:10.1080/17430437.2015.1124569

Kay, T. (2012). Accounting for legacy: Monitoring and evaluation in sport in development relationships. Sport in Society, 16(6), 888-904.

Kelly, L. (2011). Social inclusion through sports based interventions? Critical Social Policy, 31(1), 126-150.

Kennelly, J. (2016). Symbolic violence and the Olympic Games: Low income youth, social legacy commitments, and urban exclusion in Olympic host cities. Journal of Youth Studies. doi:10.1080/ 13676261.2016.1206868

Kruse, S. E. (2006). Review of kicking AIDS out. Is sport an effective tool in the fight against HIV/AIDS? Oslo, Norway: NORAD.

Lawson, A. (2005). Empowering people, facilitating community development, and contributing to sustainable development: The social work of sport, exercise, and physical education programs. Sport, Education and Society, 10(1), 135-160.

Mruk, C. (2013). Self-esteem and positive psychology. Research, theory and practice. New York, NY: Springer.
Mwaanga, O., \& Prince, S. (2016). Negotiating a liberative pedagogy in sport development and peace: understanding consciousness raising through the Go Sisters programme in Zambia. Sport, Education and Society, 21(4), 588-604. doi:10.1080/ 13573322.2015.1101374

Oproep Voor een Democratische School. (2014). PISA 2012 ontsluierd: De naakte cijfers. Waarom zijn België en Frankrijk de kampioenen van sociale ongelijkheid in het onderwijs? Brussels, Belgium: Studiedienst OVDS.

Pajares, F. (1996). Self-efficacy beliefs and mathematical problem-solving of gifted students. Contemporary Educational Psychology, 21, 325-344.

Parnell, D., Spracklen, K., \& Millward, P. (2016). Special Issue Introduction: Sport management issues in an era of austerity. European Sport Management Quarterly. doi:10.1080/16184742.2016. 1257552

Pawson, R. (2006). Evidence-based policy: A realist perspective. London, UK: Sage.

Rosenberg, M. (1965). Society and the adolescent selfimage. Princeton, NJ: Princeton University Press.

Rossi, T., \& Jeanes, R. (2016). Education, pedagogy and sport for development: Addressing seldom asked questions. Sport, Education and Society, 21(4), 483494. doi:10.1080/13573322.2016.1160373

Rossi, P. H., Lipsey, M. W., \& Freeman, H. E. (2004). Evaluation. A systematic approach. London, UK: Sage Publishing.

Schmitt, D. P., \& Allik, J. (2005). Simultaneous administration of the Rosenberg self-esteem scale in 53 nations: exploring the universal and culture-specific features of global self-esteem. Journal of Personality and Social Psychology, 89(4), 623-642.

Schulenkorf, N., Sherry, E., \& Rowe, K. (2016). Sport for Development: An integrated literature review. Journal of Sport Management, 30(1), 22-39. doi:10.1123/jsm.2014-0263

Schulenkorf, N., \& Spaaij, R. (2016). Commentary: Reflections on theory building in Sport for Development and peace. International Journal for Sport Management and Marketing, 16(1/2), 71-77.

Sherer, M., Maddux, J. E., Mercandante, B., PrenticeDunn, S., Jacobs, B., \& Rogers, R. W. (1982). The SelfEfficacy Scale: Construction and validation. Psychological Reports, 51(2), 663-671.

Spaaij, R., Oxford, S., \& Jeanes, R. (2016). Transforming communities through sport? Critical pedagogy and sport for development. Sport, Education and Society, 21(4), 570-587. doi:10.1080/ 13573322.2015.1082127

UNDP. (2017). Human Development Report 2015. Retrieved from http://hdr.undp.org/sites/default/files/ 2015_human_development_report.pdf

Vallieres, E., \& Vallerand, R. (1990). Traduction et validation Canadienne-Française de l'échelle de l'estime de soi de Rosenberg. International Journal of Psychology, 25(2), 305-316. 
Vertovec, S. (2007). Super-diversity and its implications. Ethnic and Racial Studies, 30(6), 1024-1054.

Vettenburg, N. (1998). Juvenile delinquency and the cultural characteristics of the family. International Journal of Adolescent Medicine and Health, 10(3), 193-210.

\section{About the Authors}

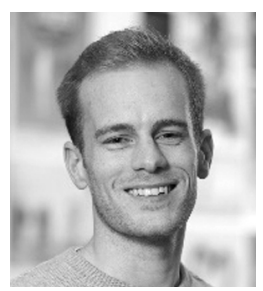

Zeno Nols has a Master's degree in Sociology. He holds an additional Postgraduate degree in Sport Management. In 2014, Zeno started his PhD, in which he critically investigates the value of sport for young people in precarious situations within super-diverse urban contexts. He focuses on the underlying pedagogies and the impact of six urban sport-for-development initiatives. Zeno is also involved in other research projects regarding specific themes (e.g., migration, detention, employment).

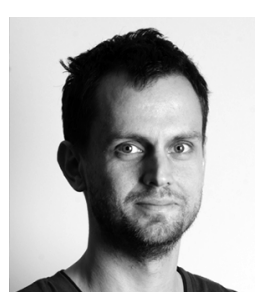

Reinhard Haudenhuyse holds Master's degrees in Physical Education and in Conflict and Development, both from Ghent University. In 2012 he received his PhD in Physical Education and Movement Sciences at the Vrije Universiteit Brussel. He currently works as a part-time professor and post-doctoral researcher at the Sport and Society Research Unit and the Interdisciplinary Research Group Voicing At-Risk Youth at Vrije Universiteit Brussel.

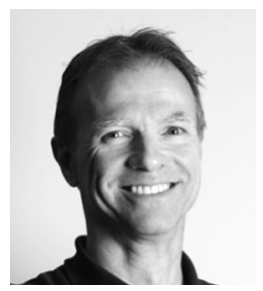

Marc Theeboom holds a PhD in Physical Education and a Master's degree in Leisure Studies. He works as a full professor at the Vrije Universiteit Brussel. He is chair of the "Sport and Society" Research Group and of the Department of Sport Policy and Management. Since 2010, Marc has been the promotercoordinator of the Flemish Policy Research Centre for Sports (Steunpunt Sport). His research primarily focuses on policy-related and pedagogical aspects of sport in general, as well as in relation to specific target groups in particular. Since 2016, Marc has been co-promoter of the large-scale interdisciplinary 'CATCH' research program (“Community sports for AT-risk youth: innovative strategies for improving personal development, health and soCial cohesion"). 